\title{
Aeolian Processes and Landforms Across the Solar System: Science and Technology Requirements for the Next Decade
}

\author{
Corresponding Author: Timothy N. Titus (U.S. Geological Survey; ttitus@usgs.gov)
}

Co-authors: Serina Diniega (Jet Propulsion Laboratory, California Institute of Technology), Lori Fenton (Carl Sagan Center, SETI Institute, Mountain View, CA), Lynn Neakrase (Astronomy Department, New Mexico State University, Las Cruces, NM), Jaap Nienhuis (Department of Physical Geography, Utrecht University, Utrecht, Netherlands), Jani Radebaugh (Department of Geological Sciences, Brigham Young University, Provo, UT), Kaj E. Williams (U.S. Geological Survey), James Zimbelman (National Air and Space Museum, Smithsonian Institution, Washington, DC)

Acknowledgement: A portion of the research was carried out at the Jet Propulsion Laboratory, California Institute of Technology, under a contract with the National Aeronautics and Space Administration (80NM0018D0004).

Signatories: Candice Bedford (Lunar and Planetary Institute), Mackenzie Day (University of California, Los Angeles), Stefano Nerozzi (University of Arizona), Claire Newman (Aeolis Research), Luca Montabone (Space Science Institute), Kenneth Herkenhoff (US Geological Survey), Isaac B. Smith (Planetary Science Institute), Alexey Pankine (Space Science Institute), Ganna (Anya) Portyankina (University of Colorado), Briony Horgan (Purdue University), Laura Kerber (Jet Propulsion Laboratory), Cecilia Leung (Jet Propulsion Laboratory, California Institute of Technology), Shannon Hibbard (Western University), Daniela Tirsch (Deutsches Zentrum für Luft- und Raumfahrt (DLR)), Matthew Chojnacki (Planetary Science Institute), Daniel Viudez Moreiras (INTA-CSIC), Kim Seelos (John Hopkins University Applied Physics Laboratory), Charlene Detelich (University of Alaska - Anchorage), Nathaniel Putzig (Planetary Science Institute). 
I. Introduction and Motivation. Aeolian processes and phenomena have sculpted landscapes and influenced planetary climate states across the Solar System, including planetary bodies with transient atmospheres (Fig. 1). For planetary purposes, an aeolian process refers to interactions between a moving fluid and a granular surface (sediment) where usually the fluid is a planetary atmosphere. Depending on atmospheric and surface conditions (e.g., gravity, atmospheric density, and viscosity), the best terrestrial analogs could be subaqueous activity (e.g., Venus Fig. 1e, f), snow fields, or pyroclastic flows (e.g., comets or other Solar System objects with transient atmospheres). Common transport mechanisms are creep (rolling on the surface), saltation (hopping), and suspension. These transport mechanisms construct landforms, erode landscapes, and produce a wide range of morphologies with scales ranging from centimeters to thousands of kilometers.

Aeolian processes often modify landforms constructed by other processes. Aeolian landforms, in turn, are often modified by other processes, hence having a cyclical relationship. These multiple and layered interactions provide an opportunity for interdisciplinary research but are also a challenge to disentangle geologic and climate conditions; that is, the distant past, the recent past, and the present may be simultaneously recorded. The principle of equifinality may further complicate interpretations, with different processes potentially leading to similar morphologies (Beven, 1996). Expertise from a variety of fields is needed to understand what is being observed and includes, but is not limited to, meteorology, climate science, astrobiology, geology, planetary protection, and polar science. These other disciplines must also consider the effects of aeolian processes within their studies. In many ways, planetary aeolian processes and phenomena (e.g., Table 1) are ideal for comparative planetology because such qualitatively well-

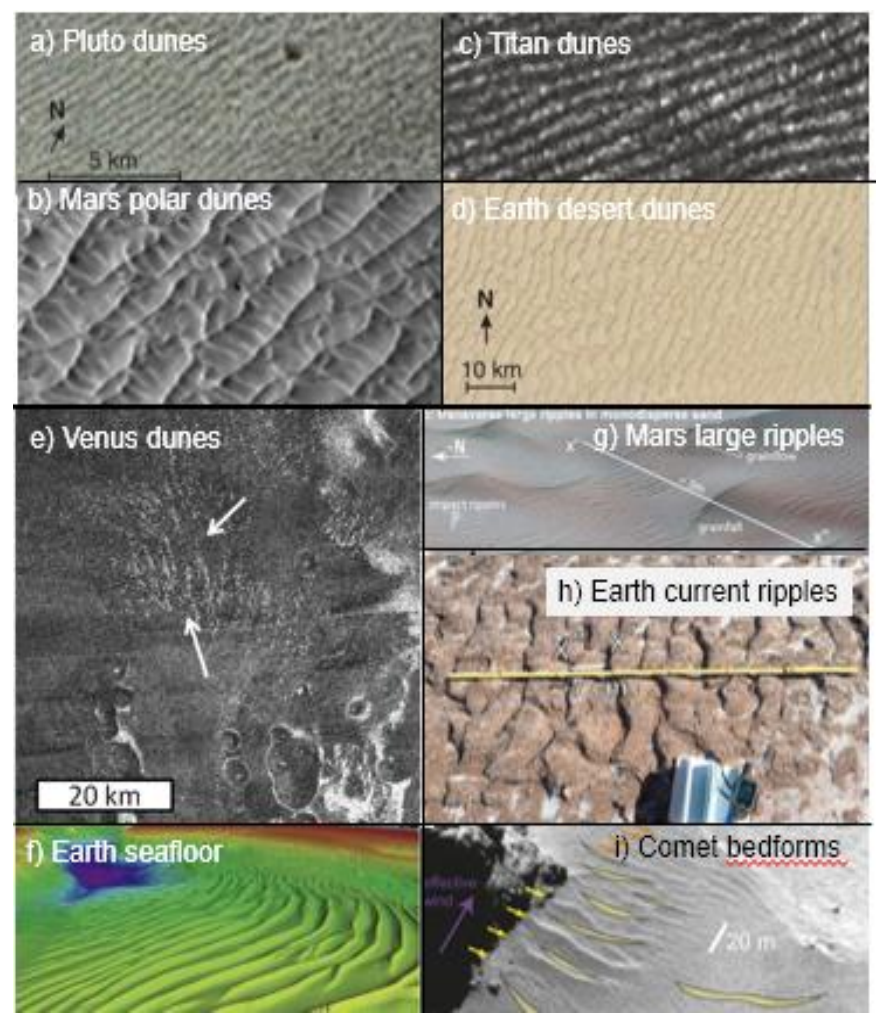

Figure 1: Examples of aeolian features on different planetary bodies: (a-d) Planetary features with remarkable geomorphic similarities, leading to hypotheses of aeolian dune fields. (e-j) Examples from the diverse suite of bedforms found on other bodies, which may be more analogous to terrestrial subaqueous bedforms than subaerial ones (proposed terrestrial analogs are shown in $f$ and $h$, for Venus and Mars/comet, respectively). Image credits: (a) Telfer et al., 2018, (b-d) Diniega et al. 2017, (e, f) Neakrase et al., 2017, $(\mathrm{g}, \mathrm{h})$ Lapotre et al., 2018, (i) Jia et al., 2017. 
understood processes appear to be acting across numerous bodies and generating similar morphologies.

Finally, aeolian processes can be both an asset and a hazard to both robotic and future human exploration. An excellent example is Mars' solar-powered rovers. A large-scale dust storm can obscure the sun and coat solar panels with dust, thus starving the rover of both operational and sustainment power. However, dust devils in turn can clean the solar panels, thus increasing both the power generation capability and mission duration. A better understanding of planetary aeolian processes and phenomena is needed to ensure less risk and greater resiliency for future missions - both robotic and human.

II. Goals and Objectives. Discussions of planetary atmosphere-surface interactions (including aeolian processes, phenomena, and the resulting landforms) are often tied to a specific planetary body. Considering this, a series of workshops were initiated in 2008 to facilitate an interdisciplinary and interplanetary body approach to further our understanding of these atmosphere-surface interactions (Titus et al., 2008, 2010, 2012, 2015, 2017). The most recent workshop, held 12-13 May 2020, transitioned to a virtual format due to the COVID-19 pandemic, with a specific focus on the planetary aeolian community's vision for the next decade. Discussions centered around dynamics and resulting landforms, missions and models, and facilities. Participants identified the need for a planetary aeolian goals-and-objectives document that is inclusive of multiple planetary bodies, processes, and phenomena that all intersect where the surface meets the atmosphere. This white paper is the first iteration of that vision, with definitions of Goals/Objectives that organize the broad range of existing and needed planetary aeolian studies.

Goal 1. Determine where dynamic atmosphere-surface interactions have occurred as recorded by observed aeolian features/phenomena and quantify the likely amount (or volume) of sediment currently stored. (Plain language: Where are the wind-generated features and how much sediment is there?)

- Obj 1A. Identify traces of aeolian activity across the Solar System.

- Obj 1B. Quantify the areal extent and the volume of material required to produce observed features.

Goal 2. Define the processes and evolution of wind-field-dependent landforms (e.g., aeolian bedforms, wind streaks, yardangs, sastrugi) in relationship to atmospheric conditions and availability of sediment over time. (Plain language: What can we learn about current and past wind circulation patterns and the availability of sediment from the geomorphology of the landforms?)

- Obj 2A. Characterize the physical conditions and processes that control wind-fielddependent landforms under modern conditions.

- $\quad$ Obj 2B. Characterize the history, likely dynamic atmospheric-surface interaction, and processes that controlled aeolian bedforms and erosional landforms in the recent past.

- Obj 2C. Identify relevant analogs (including those constructed in the laboratory (Burr et al., 2020)) based on the specific planetary conditions (e.g., fluid viscosity, fluid/particle density ratio, dimensionless numbers such as Reynolds number). 
Goal 3. Use aeolian depositional and erosional landforms/strata to aid geologic and paleoclimate reconstructions. (Plain language: What do landforms tell us about planetary history?)

- Obj 3A. Determine how ancient aeolian bedforms and erosional landforms may be recognized within planetary sedimentary records.

- Obj 3B. Determine the inventory, sources, sinks, and composition of available sediment.

- Obj 3C. Document how aeolian features and phenomena are incorporated into and preserved in the geologic record.

- Obj 3D. Determine the potential for biopreservation in ancient aeolian materials (on Earth, fossils and oil are often found in aeolian sediments).

- Obj 3E. Determine aeolian erosion rates of different geologic materials (is this why Titan has so few craters?) to determine exposure times.

Goal 4. Determine potential risks and other operational considerations that planetary aeolian processes and landforms present for robotic and human exploration. (Plain language: What risks and opportunities do processes generated by wind pose for robotic and future human exploration?)

- Obj 4A. Increase our capability to predict and model environmental aeolian hazards (e.g., dust storms, sand abrasion, electrostatics) in order to protect human and robotic explorers.

- Obj 4B. Increase our capability to access aeolian-derived or -modified landscapes in order to reduce operations and mobility risks to human and robotic explorers. (Plain language: Avoid getting stuck in sand or dust! Aid in situ resource utilization (ISRU) system designs in a sandy/dusty environment.).

- Obj 4C. Determine the likelihood of forward contamination by aeolian processes (e.g., rafting of microbes on dust grains) to ensure planetary protection.

The goals are organized by mission/technological complexity, where Goal 1 can generally be accomplished with visible imagery or active radar data taken from orbital or flyby spacecraft. Goal 2 generally requires high resolution imagery or active radar acquired from orbit. Aerial platforms (helicopters) would provide additional capabilities. Goal 3 generally requires both orbital remote sensing (beyond visible to include (but not limited to) near-infrared, short-wave infrared, thermal, and gamma ray) and in situ analysis. Goal 4 generally requires in situ capabilities, but also includes atmospheric monitoring from orbit.

Table 1: Examples of planetary aeolian features or phenomena.

\begin{tabular}{|l|l|l|l|l|}
\hline $\begin{array}{l}\text { Feature or } \\
\text { Phenomena }\end{array}$ & $\begin{array}{l}\text { Formation } \\
\text { timescale }\end{array}$ & $\begin{array}{l}\text { Size (Spatial } \\
\text { Scale) }\end{array}$ & Process & Planetary body \\
\hline Dust devils & Minutes & $10-1000 \mathrm{~m}$ & Convection & Earth, Mars \\
\hline Dust storms & $\begin{array}{l}\text { Hours to } \\
\text { months }\end{array}$ & $1-1000 \mathrm{sm}$ & Suspension & Earth, Mars, Titan \\
\hline $\begin{array}{l}\text { Streaks formed } \\
\text { from gas jets }\end{array}$ & Hours to days & $1-10 \mathrm{~km}$ & $\begin{array}{l}\text { Polar/ } \\
\text { sublimation }\end{array}$ & Mars, Triton \\
\hline
\end{tabular}




\begin{tabular}{|l|l|l|l|l|}
\hline $\begin{array}{l}\text { Wind streaks/rock } \\
\text { wind tails }\end{array}$ & $\begin{array}{l}\text { Seasonal-100s } \\
\mathrm{yr}\end{array}$ & $\begin{array}{l}0.01-1000 \\
\mathrm{~km} / 0.01-10 \mathrm{~s} \\
\mathrm{~m}\end{array}$ & $\begin{array}{l}\text { Erosional, } \\
\text { depositional, } \\
\text { sometimes both }\end{array}$ & $\begin{array}{l}\text { Mars, Venus, Earth, } \\
\text { Pluto, Triton? }\end{array}$ \\
\hline Ripples & sec to hours & $0.01-10 \mathrm{~s} \mathrm{~m}$ & Saltation & Earth, Mars, comet P/69 \\
\hline Megaripples & Decades & $0.01-10 \mathrm{~s} \mathrm{~m}$ & Traction & Earth, Mars \\
\hline $\begin{array}{l}\text { TARs and other } \\
\text { enigmatic bedforms }\end{array}$ & 10s yr-Ka & $1-100 \mathrm{~s} \mathrm{~m}$ & $\begin{array}{l}\text { Saltation with } \\
\text { traction }\end{array}$ & Mars, Earth \\
\hline Dunes & $1 \mathrm{yr}-\mathrm{Ma}$ & $\begin{array}{l}0.01-1000 \mathrm{~s} \\
\mathrm{~km}\end{array}$ & Saltation & $\begin{array}{l}\text { Venus, Earth Mars, } \\
\text { Titan, Pluto?, lo? }\end{array}$ \\
\hline Megadunes & Ma & $10-1000 \mathrm{~s} \mathrm{~km}$ & Saltation & Earth, Mars, Titan \\
\hline Lunettes & Ka-Ma & $0.1-10 \mathrm{sm}$ & Lacustrine & Earth \\
\hline Ventifacts & Ka-Ma & $0.01-10 \mathrm{~m}$ & Erosional & Earth, Mars \\
\hline $\begin{array}{l}\text { Yardangs } \\
\text { Ka-Ma }\end{array}$ & $\begin{array}{l}1 \mathrm{~m}-100 \mathrm{~s} \mathrm{~km} \\
\text { Erosional }\end{array}$ & $\begin{array}{l}\text { Earth, Mars, Venus, } \\
\text { Titan }\end{array}$ \\
\hline Sastrugi & $\mathrm{minutes}$ to days & $0.01-10 \mathrm{~s} \mathrm{~m}$ & Niveo-aeolian & Earth, Mars [1] \\
\hline $\begin{array}{l}\text { Abraded landscapes } \\
\text { (e.g., inverted } \\
\text { topography) }\end{array}$ & Ma & $\begin{array}{l}0.01-1000 \mathrm{~s} \\
\mathrm{~km}\end{array}$ & Erosional & $\begin{array}{l}\text { Earth, Mars [2], Venus, } \\
\text { Titan? }\end{array}$ \\
\hline $\begin{array}{l}\text { Deflation hollows } \\
\text { and basins }\end{array}$ & Ma & $1-100 \mathrm{~s} \mathrm{~km}$ & Erosional & Earth, Mars, Titan? \\
\hline $\begin{array}{l}\text { Duststone/loess } \\
\text { deposits }\end{array}$ & Ka-Ma & $1-100 \mathrm{~s} \mathrm{km?}$ & Depositional & Earth, Mars [3] \\
\hline $\begin{array}{l}\text { Sand sheets } \\
\text { Aeolian sandstones }\end{array}$ & Ka-Ma & $1-1000 \mathrm{~s} \mathrm{~km}$ & Depositional & $\begin{array}{l}\text { Titan [4], Earth [5], } \\
\text { Mars [6] }\end{array}$ \\
\hline
\end{tabular}

Table notes: [1] Rodriguez et al., 2017. [2] Farley et al., 2014 [3] Kreslavsky and Head, 2002

[4] Lopes et al., 2016. [5] Kocurek, G., \& Nielson, J. (1986) [6] Runyon et al., 2017.

III. Exploration Roadmap for the Next Decade. Planetary aeolian studies not only span the Solar System, but also the range of research methods, including remote sensing, analog field studies, numerical modeling, laboratory experiments, and more recently, planetary in situ studies. Recent and future in situ studies on Mars are of enough detail and sophistication that these could be considered studies of new "analog sites" (e.g., Diniega et al., 2020a, b).

Individually, each research approach brings new knowledge, but the synergy of these combined approaches brings new understanding. Greeley \& Iversen (1985) proposed a similar integrated approach (or framework) to aeolian studies which proved to be very successful. The research framework proposed by Diniega et al. (2017), with a focus on dunes and dune fields, expanded on these ideas by adding an in situ component. Fig. 2 is a simplified version of this framework.

The goals and objectives, as outlined in section II, are best addressed using a combination of approaches (or integrated framework) to achieve the greatest results.

Goal 1, conducting a Solar System inventory of aeolian activity, can be achieved with medium resolution (10-100 m/pix) global surveys combined with follow-up, high-spatial resolution (1-10 m/pix) imagery. For some planetary bodies with opaque atmospheres, such as Venus or Titan, radar may be used instead of a visible imaging system. For example, a Mars 
Global Digital Dune Database (MGD ${ }^{3}$, Hayward et al., 2007) was generated using near-global Thermal imaging (100/pix). This work initially identified 2000 medium to large dune fields and their aerial extent; later surveys based on HiRISE imaging has yielded identification of another 2000 smaller dune fields (Fenton, 2020).

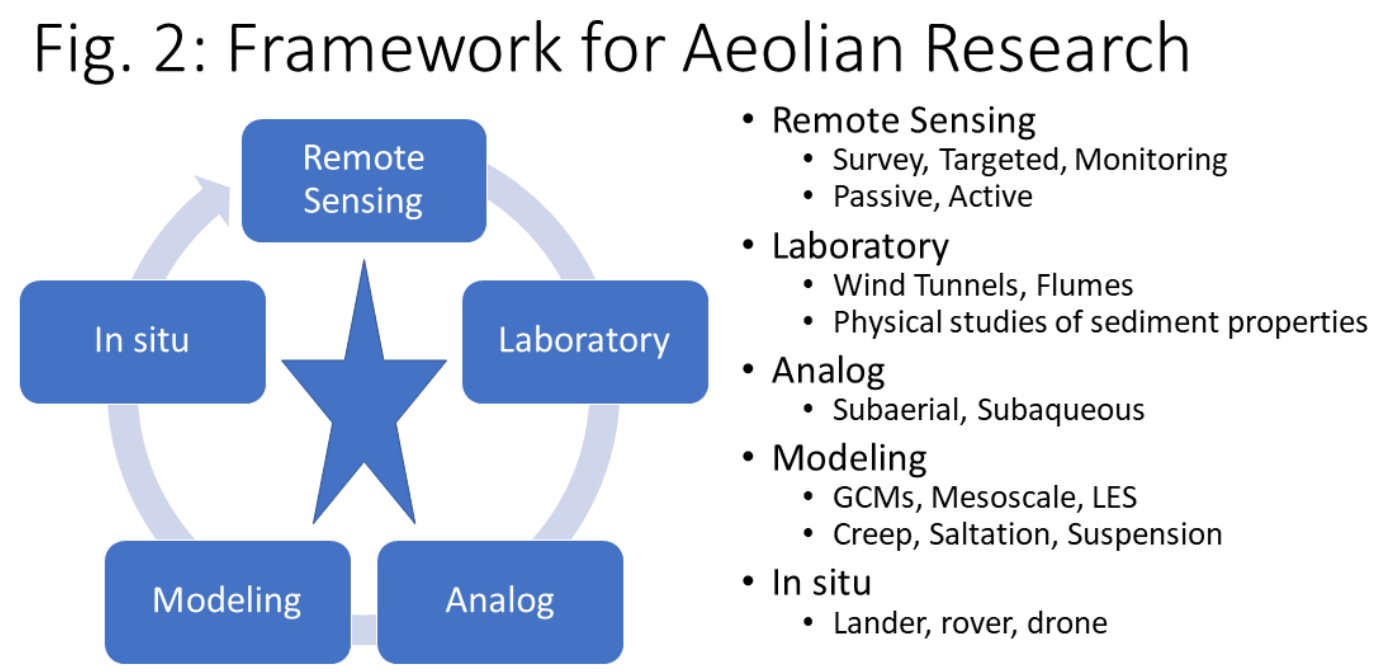

Goal 2, using high resolution imagery of aeolian feature morphologies, can be achieved with high spatial resolution imaging with stereo capability, or active sensors that can determine topography (lidar, radar). Continuing with $\mathrm{MGD}^{3}$ as an example, higher resolution MOC imagery was used to determine wind directions from morphology, and MOLA topography was used to estimate volume. The $\mathrm{MGD}^{3}$ was also provided to the Mars HiRISE operation team for added guidance in targeting. This resulted in a rich dataset of Mars dunes and through repeat imaging, ultimately demonstrated that some dunes on Mars are still active (Fenton et al., 2006; Bourke et al., 2008). The interpretation of these spacecraft datasets is supported by analog studies, computer simulations, and experiments (such as wind tunnel experiments).

Goal 3 can be accomplished with a combination of orbital and landed assets. Infrared imaging spectroscopy (both reflection and thermal) can provide global datasets concerning composition, grain size, and cementation state. In situ studies provide local field site validation for the global datasets. For Mars, the sediment is basaltic but there is still a debate as to whether the sediment source is local or regional (e.g., Fenton et al., 2019). The sediment on Titan appears to be organic (McCord et al., 2006), but the exact source of saltatable grains is still under investigation.

New capabilities are coming online over the next decade that incorporate multiple approaches. The Mars 2020 Helicopter and the Titan Dragonfly are examples of planetary drones where remote sensing and in situ studies will be conducted by the same platform.

Networks of meteorological stations designed to monitor the atmospheric surface layer would provide needed data on the direct atmospheric interaction with the granular surface. Even one station that can concurrently measure both sediment flux and environmental drivers, so as to characterize the full surface-atmosphere interaction and calibrate/test models of such processes would fill a critical gap in our understanding of aeolian phenomena. The measurements needed 
are temperature, humidity, pressure, 3D winds, and saltation profiles (Diniega et al., 2020). For example, Beagle 2 (a British Mars lander) included a piezoelectric saltation sensor.

Goal 4 is more operationally based but makes use of the same types of data collected for Goal 3. Aeolian processes can be either be a hazard to exploration (e.g., dust can reduce the efficiency of solar panels) or an opportunity to be leveraged (e.g., dust devils cleaning solar panels). In the case of Mars, planet-encircling dust storms (PEDS) can terminate not just robotic operations, but the robotic platform itself due to extended periods of insufficient insolation for power, even in hibernation. However, we currently lack the capability to predict when a PEDS might occur (Newman et al., 2020).

For aeolian studies, each planetary body is in a different stage of exploration and understanding. Table 2 identifies which spacecraft/instruments could be flown and which of the four goals could be addressed over the next decade. This table is not meant to be all encompassing but to provide examples of what could be achieved.

Table 2: Planetary Aeolian Questions for the next decade.

\begin{tabular}{|l|l|l|l|}
\hline $\begin{array}{l}\text { Planetary } \\
\text { Body }\end{array}$ & $\begin{array}{l}\text { Needed in Next } \\
10 \text { Years }\end{array}$ & $\begin{array}{l}\text { Goals } \\
\text { Supported }\end{array}$ & Driving Science Questions \\
\hline Venus & Imaging Radar & 1,2 & $\begin{array}{l}\text { Are there more dunefields than the two observed by } \\
\text { Magellan? }\end{array}$ \\
\hline Mars & $\begin{array}{l}\text { Landed } \\
\text { Meteorological } \\
\text { monitoring, } \\
\text { Continued High } \\
\text { Resolution } \\
\text { Imaging, } \\
\text { Lidar/SAR/IR, } \\
\text { Drones, Wind } \\
\text { measurements, } \\
\text { from the surface } \\
\text { to the PBL }\end{array}$ & $1,2,3,4$ & $\begin{array}{l}\text { What is the physics within the atmospheric surface } \\
\text { layer that determines the initiation of a regional or } \\
\text { global dust storm? Under what mechanisms and to } \\
\text { what heights does dust get lofted? How many dunes } \\
\text { are currently active? What are the modern global } \\
\text { circulation patterns at the surface? }\end{array}$ \\
\hline lo & Orbiter Imaging & 1,2 & $\begin{array}{l}\text { For the fundamental physics: what is the sand } \\
\text { grain/velocity profile and height achieved by the } \\
\text { saltation cloud? Under what conditions is dust lofted } \\
\text { and at what rate? What is the variation in sediment? }\end{array}$ \\
\hline Titan & $\begin{array}{l}\text { Drones, Orbiters } \\
\text { Imaging/SAR }\end{array}$ & $1,2,3$ & $\begin{array}{l}\text { Where are there bedforms? What are they made of? } \\
\text { Pluto }\end{array}$ \\
\hline Comets & $\begin{array}{l}\text { Imaging } \\
\text { old are the dunes and other aeolian deposits? }\end{array}$ \\
\hline
\end{tabular}

\section{References}


Beven, K. (1996) Equifinality and Uncertainty in Geomorphological Modelling, in The Scientific Nature of Geomorphology: Proceedings of the 27th Binghamton Symposium in Geomorphology Edited by Bruce L. Rhoads and Colin E. Thorn, John Wiley \& Sons Ltd.

Bourke, M. C., Edgett, K. S., \& Cantor, B. A. (2008). Recent aeolian dune change on Mars. Geomorphology, 94(1-2), 247-255. https://doi.org/10.1016/j.geomorph.2007.05.012

Diniega, S., Bramson, A., Buratti, B., et al., 2020a, Mars as a "natural laboratory" for studying surface activity on a range of planetary bodies, a white paper submitted to the Planetary Decadal Survey.

Diniega, S., Burr, D., Dundas, C., et al., 2020b, A Critical Gap: In situ Measurements of Planetary Surface-Atmosphere Interactions Beyond Earth, a white paper submitted to the Planetary Decadal Survey.

Diniega, S., Krevalevsky, M., Radebaugh, J., et al., 2017, Our evolving understanding of aeolian bedforms, based on studies of different worlds. Aeolian Research (special issue: Planetary Dunes), 26, 5-27, doi:10.1016/j.aeolia.2016.10.001.

Farley, K., Malespin, C., Mahaffy, P., et al., 2014, In situ Radiometric and Exposure Age Dating of the Martian Surface. Science, 343(6169), id. 1247166.

Fenton, L. K. (2006). Dune migration and slip face advancement in the Rabe Crater dune field, Mars. Geophysical Research Letters, 33(20), 1-5. https://doi.org/10.1029/2006GL027133

Fenton, 2020, Adding New, Smaller Dune Fields to the Mars Global Digital Dune Database Inventory, Sixth International Planetary Dunes Workshop, \#3013.

Fenton, L. K., Gullikson, A. L., Hayward, R. K., Charles, H., \& Titus, T. N. (2019). The Mars Global Digital Dune Database (MGD3): Global patterns of mineral composition and bedform stability. Icarus, 330, 189-203. https://doi.org/10.1016/j.icarus.2019.04.025

Greeley, R. \& Iversen, J. (1985). Wind as a Geologic Process: On Earth, Mars, Venus and Titan (Cambridge Planetary Science Old). Cambridge: Cambridge University Press. doi:10.1017/CBO9780511573071.

Hayward, R., Mullins, K., Fenton, L., et al., 2007, Mars Global Digital Dune Database and initial science results. Journal of Geophysical Research, 112(E11), CiteID E11007

Kocurek, G., \& Nielson, J. (1986). Conditions favourable for the formation of warm-climate aeolian sand sheets. Sedimentology, 33(6), 795-816.

Kreslavsky, M. and Head, J., 2002, Mars: Nature and evolution of young latitude-dependent water-icerich mantle. Geophysical Research Letters, 29(15), CiteID 1719.

Laporte M., Ewing, R., Weitz, C., et al., 2018, Morphological diversity of the martian ripples: implications for large-ripple formation. Geophysical Research Letters, 45, 10229.

Lopes, R. M. C., Malaska, M. J., Solomonidou, A., Le Gall, A., Janssen, M. A., Neish, C. D., ... Lawrence, K. J. (2016). Nature, distribution, and origin of Titan's Undifferentiated Plains. Icarus, 270, 162-182. doi:10.1016/j.icarus.2015.11.034

McCord, T. B., et al. (2006), Composition of Titan's surface from Cassini VIMS. Planet. Space Sci., 54, 1524-1539, doi:10.1016/j.pss.2006.06.007

Neakrase, L., Klose, M., Titus, T., 2017, Terrestrial subaqueous seafloor dunes: Possible analogs for Venus. Aeolian Research, 26, 47-56.

Newman, C., et al., 2020, Toward more realistic simulation and prediction of dust storms on Mars, a white paper submitted to the Planetary Decadal Survey.

Rodriguez, J., Tanaka, K., Yves, Y., et al., 2007, Recent aeolian erosion and deposition in the north polar plateau of Mars. Mars 3, 29-41.

Runyon, K. D., Bridges, N. T., \& Newman, C. E. (2017). Martian sand sheet characterization and implications for formation: A case study. Aeolian Research, 29(April), 1-11.

Telfer, M.W., E. J. R. Parteli, J. Radebaugh, et al., 2018, Dunes on Pluto, Science, 360(6392) 992-997. 